\title{
Level of Athlete's Health and Blood Pressure Variability
}

\author{
Romanchuk AP*1 and Guzii OV ${ }^{2}$ \\ ${ }^{1}$ International Humanitarian University, Odesa, Ukraine
}

${ }^{2}$ Lviv State University of Physical Culture, Lviv, Ukraine

Received: 些: October 09, 2018; Published: 鴊: October 24, 2018

*Corresponding author: Romanchuk AP, International Humanitarian University, Odesa, Ukraine

\section{Abstract}

To determine of the parameters of the systolic (SBPV) and diastolic (DBPV) blood pressure variability dependent on the level of the athletes' health $(\mathrm{H})$ "Spiroarteriocardiorhythmograph" was used. 104 male athletes, at the age of $20.6 \pm 0.9$, who were engaged in various sports, were analyzed. Taking into account the level H, they were divided into 3 groups: the first group with a high-level H was 39 people ("high"), the second group was 46 ("average"), the third group was 19 ("low"). This report analyzes the differences in the ranks of the parameters of the SBPV and DBPV - TPSBP $\left(\mathrm{mmHg}^{2}\right)$, VLFSBP $\left(\mathrm{mmHg}^{2}\right)$, LFSBP $\left(\mathrm{mmHg}^{2}\right)$, HFSBP $\left(\mathrm{mmHg} \mathrm{g}^{2}\right), \mathrm{LF} / \mathrm{HFSBP}\left(\mathrm{mmHg}^{2} / \mathrm{mmHg}^{2}\right)$, TPDBP $\left(\mathrm{mmHg}^{2}\right), \mathrm{VLFDBP}\left(\mathrm{mmHg}^{2}\right), \mathrm{LFDBP}^{2}$ $\left(\mathrm{mmHg}^{2}\right)$, HFDBP $\left(\mathrm{mmHg}^{2}\right)$, LF/HFDBP $\left(\mathrm{mmHg}^{2} / \mathrm{mmHg}^{2}\right)$.

There were no possible differences in any registered SBPV values. We can speak about the reducing tendency in regulatory influences in all frequency grades, with the exception of high-frequency ones (HFSBP $\mathrm{mmHg}^{2}$ ), which is invalid tendency. After analyzing the DBPV data it becomes clear that in terms of VLFDBP $\left(\mathrm{mmHg}^{2}\right)$ possible differences between "high" and "low" are quite pronounced.

Keywords: Blood pressure variability; Sportsmen; Health

\section{Introduction}

The problem of finding informational criteria of the athlete's health is related to the possibilities of expressing determination and evaluation of functional parameters, primarily cardiovascular and respiratory systems, which would allow to measure and characterize the functional support and functional reserves of the organism [1-5].

The important indicator of the $\mathrm{H}$ of the athletes is blood pressure, which, in combination with the parameters of heart rate (HR), characterizes the hemodynamic provision of the organism $[6,7]$. Absolute values of systolic and diastolic pressure, as well as their derivatives, indirectly determine the cardiac output power, the nature of vascular resistance, the volume of circulating blood, etc. [8-10]. Analysis of the pulse wave allows, in view of the point of registration of blood pressure, to characterize the time of its delay, the stiffness of the vascular wall and a number of other functional indices, indicating the passage of blood volume through the vessels and characterizing the state of the vascular wall [11-13]. In the sport practice, it is important to determine these indicators to identify conditions of fatigue, overstrain, overtraining, when in the conditions of the training and competitive process it is necessary to change quickly and qualitatively the direction of training or recovery of the organism after them $[5-7,12,14,15]$. The study of the variability of blood pressure according to the recording of the pulse wave on each heartbeat by photoplethysmographic method has been used for a long time, but, due to various circumstances, it has not been widely used [16-19]. We will try to fill this gap to some extent.

Ourattention wasdrawn tothemultifunctionalmethodofstudying the state of the organism - "Spiroarteriocardiorhythmography" (SACR), which, in the simultaneous registration mode, allows to determine the function of the heart, blood vessels and respiration $[20,21]$. Previously, we have analyzed the changes in the parameters of the heart rate variability for the influence of the cycle of training loads both before and after the training load, which allowed to establish their peculiarities in the development of training and taking into account the response to standard physical activity $[3,4,14,15,22,23]$. The purpose of this study was to determine the peculiarities of the parameters of the SBPV and DBPV depending on the level of the athlete's health.

\section{Material \& Methods}

For this purpose, 104 male athletes, age $20.6 \pm 0.9$ years old, who were engaged in various sports, were analyzed for the SBPV and DBPV indices. Taking into account the level of the $\mathrm{H}$, they were divided into 3 groups: first group with a high level of $\mathrm{H}$ was 39 people ("high"), second group - 46 ("average"), third group - 19 ("low"). 
To determine the athlete's health, we used the system of assessment of the level of somatic health (LSH) by GL Apanasenko, which has a close connection with V02max of the body. Thus, the low level of LSH corresponds to VO2max: $16 \pm 7 \mathrm{ml} / \mathrm{min} . \times \mathrm{kg}$, below the average: $23 \pm 8 \mathrm{ml} / \mathrm{min} \times \mathrm{kg}$, an average: $29 \pm 4 \mathrm{ml} / \mathrm{min} \times \mathrm{kg}$, above the average: $41 \pm 3 \mathrm{ml} / \mathrm{min} \times \times \mathrm{kg}$, and high: $62 \pm 6 \mathrm{ml} / \mathrm{min} \times \mathrm{kg}$. In determining the level of the $\mathrm{H}$, high and higher LSH levels were characterized as "high" H, average LSH as the "average" H, low and lower than average LSH as "low" H [1]. Non-parametric methods of statistical analysis with determination of Mann-Whitney criterion were used to evaluate the obtained results of the study. Table 1 shows the average data of the analysis of measurements of the parameters of the body structure of athletes of the studied groups.

Table 1: Characteristics of physical development parameters of studied groups, $M\left(Q_{1} ; Q_{3}\right)$.

\begin{tabular}{|c|c|c|c|}
\hline Parameters & High & Average & Low \\
\hline Weight, $\mathrm{kg}$ & $71.0(69.0 ; 78.0)^{*}$ & $75.5(70.0 ; 80.0)$ & $77.0(72.0 ; 80.0)$ \\
\hline Length, cm & $178.0(175.0 ; 181.0)$ & $179.0(174.0 ; 182.0)$ & $180.0(175.0 ; 182.0)$ \\
\hline BMI, kg /m² & $22.7(21.6 ; 23.7)$ & $23.7(22.0 ; 24.9)$ & $23.5(22.5 ; 24.2)$ \\
\hline Dynamometry of wrists r., kg & $50.0(46.0 ; 54.0)$ & $48.0(44.0 ; 52.0)$ & $48.0(42.0 ; 52.0)$ \\
\hline Dynamometry of wrists l., kg & $46.0(42.0 ; 50.0)$ & $47.0(42.0 ; 52.0)$ & $48.0(42.0 ; 49.0)$ \\
\hline SI, \% & $70.4(65.6 ; 77.9)^{*} \#$ & $65.7(61.1 ; 67,7)$ & $60.5(57.6 ; 67.5)$ \\
\hline VLC, $\mathrm{ml}$ & $4900(4550 ; 5500)$ & $4850(4500 ; 5150)$ & $4900(4300 ; 5500)$ \\
\hline VI, $\mathrm{ml} / \mathrm{kg}$ & $68.5(64.3 ; 72.8)^{*}$ & $65.1(61.0 ; 72.5)$ & $63.3(56.9 ; 71.8)$ \\
\hline
\end{tabular}

* - p<0.05 in comparison "High" and "Average" with "Low"; \# - p<0.05 in comparison "High" with "Average"

Analyzing the data of the structure of the body of "high" athletes, first of all, it is necessary to stress on the differences associated with $\mathrm{H}$, which is here significantly smaller $(\mathrm{p}<0.05)$ than in "low", however, not differing from "average". At the same time, according to the body mass index (BMI), which is an integral characteristic of body mass, the probable differences in the groups of athletes are not registered. Significant differences were observed in the strength index (SI) in "high" compared to "average" and "low" ( $<<0.05)$, as well as vital index (VI) compared to "low" $(\mathrm{p}<0.05)$. With regard to the latter, it should be noted that the absolute values of the VLC are not likely to differentiate the groups [20].

As can be seen from Table 2, for all indices, in the formula for calculating of which either HR or SBP parameters in a resting state are included, there are probable differences in individuals with "high" FS. This applies to Baevsky's adaptive capacity (Baevsky's
AP), Pirogova's level of physical condition (LPC), and RI, the differences between the groups "high" are probable compared to "average" and "low". However, there were no probable differences between "average" and "low" according to these indices. In view of this, special attention deserves the lack of differentiation of Skibinska's index indices, which in the studied groups do not differ at all. It is worth mentioning that its calculation includes the VLC and inhibition time, analyzing which earlier we did not establish the probable differences in the studied groups. The results of calculating the Kerdo index proved to be informative enough to show that in "high" and "average" they are significantly different from the results in "low". In addition, in "low" (with low FS), there was a fairly distinct propensity to moderate parasympathetic content, in contrast to "high" and "average", in which variants of the normotonium with a certain tendency to parasympathetic content were superior [20].

Table 2: Characteristics of the results of the measurement of cardiovascular system performance and results of the calculation of the main integral indexes used to evaluate the functional state of the organism in the studied groups $\left(\mathrm{M}_{(}\left(\mathrm{Q}_{1} ; \mathrm{Q}_{3}\right)\right)$.

\begin{tabular}{|c|c|c|c|}
\hline Parameters & High & Average & Low \\
\hline HR, min-1 & $66,2(60,8 ; 73,3)^{*}$ & $69,8(63,6 ; 77,1)^{*}$ & $77,8(65,9 ; 82,9)$ \\
\hline SBP, mmHg & $110(110 ; 120)$ & $120(110 ; 130)$ & $720(110 ; 130)$ \\
\hline DBP, mmHg & $60(60 ; 70)^{* \#}$ & $70(60 ; 80)$ & $2.06(1.90 ; 2.30)$ \\
\hline Baevsky's AP & $1.86(1.71 ; 2.01)^{* \#}$ & $0.718(0.639 ; 0.786)$ & $0.688(0.592 ; 0.786)$ \\
\hline Pirogova's LPC & $0.785(0.736 ; 0.852)^{* \#}$ & $5931(4813 ; 7500)$ & $6655(4809 ; 7840)$ \\
\hline Skibinska's index & $6578(4958 ; 8546)$ & $79.2(70.2 ; 86.4)$ & $79.2(72.0 ; 92.4)$ \\
\hline Robinson's index & $72(62.4 ; 79.2)^{* \#}$ & $-0.03(-0.17 ; 0.09)^{*}$ & $-0.17(-0.21 ; 0.09)$ \\
\hline Kerdo index & $0.00(-0.17 ; 0.09)^{*}$ & \\
\hline
\end{tabular}

* - p<0.05 in comparison "High" and "Average" with “Low"; \# - p<0.05 in comparison "high" with "Average" 
The study of the cardiorespiratory system was performed using SACR and assumed an examination for spontaneous breathing (SB). This report analyzes the differences in the ranks of the parameters of the SBPV and DBPV - TPSBP $\left(\mathrm{mmHg}^{2}\right)$, VLFSBP $\left(\mathrm{mmHg}^{2}\right)$, LFSBP $\left(\mathrm{mmHg}^{2}\right)$, HFSBP $\left(\mathrm{mmHg}^{2}\right), \mathrm{LF} / \mathrm{HFSBP}\left(\mathrm{mmHg}^{2} / \mathrm{mmHg}^{2}\right), \mathrm{TPDBP}$ (mmHg2), VLFDBP $\left(\mathrm{mmHg}^{2}\right), \mathrm{LFDBP}\left(\mathrm{mmHg}^{2}\right), \operatorname{HFDBP}\left(\mathrm{mmHg}^{2}\right)$, LF/HFDBP $\left(\mathrm{mmHg}^{2} / \mathrm{mmHg}^{2}\right)[17,24,25]$.

\section{Results and Discussion}

No probable differences were observed in any registered SBPV values that are shown in the Table 3. We can speak about the reducing tendency in regulatory influences in all frequency ranges, with the exception of low-frequency ones ( $\mathrm{LFSBP}_{\mathrm{mmHg}}{ }^{2}$ ), which is even void of tendency.

Table 3: Results of registration of systolic and diastolic blood pressure indices using SACR in the studied groups $\left(M\left(Q_{1} ; Q_{3}\right)\right)$.

\begin{tabular}{|c|c|c|c|}
\hline Parameter BPV & High & Average & Low \\
\hline $\mathrm{TP}_{\mathrm{SBP}}, \mathrm{mmHg}^{2}$ & $23,0(18,5 ; 36,0)^{*}$ & $26,0(15,2 ; 41,0)$ & $30,3(20,3 ; 47,6)$ \\
\hline $\mathrm{TP}_{\mathrm{DBP}}, \mathrm{mmHg}^{2}$ & $9,6(5,3 ; 13,7)^{*}$ & $10,9(6,3 ; 16,0)^{*}$ & $12,3(10,2 ; 21,2)$ \\
\hline $\mathrm{VLF}_{\mathrm{SBP}}, \mathrm{mmHg}^{2}$ & $6,8(4,0 ; 13,0)$ & $10,2(4,8 ; 21,2)$ & $10,9(4,8 ; 22,1)$ \\
\hline $\mathrm{VLF}_{\mathrm{DBP}}, \mathrm{mmHg}^{2}$ & $2,0(1,2 ; 3,6)^{*} \#$ & $3,8(2,3 ; 7,8)$ & $4,4(2,0 ; 7,3)$ \\
\hline $\mathrm{LF}_{\mathrm{SBP}}, \mathrm{mmHg}^{2}$ & $6,8(4,4 ; 11,6)^{*}$ & $6,3(4,4 ; 9,6)^{*}$ & $8,4(5,8 ; 15,2)$ \\
\hline $\mathrm{LF}_{\mathrm{DBP}}, \mathrm{mmHg}^{2}$ & $4,4(2,6 ; 6,8)$ & $4,2(2,3 ; 6,8)$ & $5,3(3,2 ; 7,3)$ \\
\hline $\mathrm{HF}_{\mathrm{SBP}}, \mathrm{mmHg}^{2}$ & $4,4(2,6 ; 9,0)$ & $5,1(3,2 ; 9,6)$ & $4,8(2,6 ; 12,3)$ \\
\hline $\mathrm{HFDBP}_{\mathrm{mmHg}}$ & $1,0(0,5 ; 2,3)$ & $1,0(0,6 ; 1,7)$ & $1,4(0,6 ; 2,0)$ \\
\hline $\mathrm{LFHF}_{\mathrm{SBP}}, \mathrm{mmHg} / \mathrm{mmHg}^{2}$ & $1,28(0,55 ; 4,20)$ & $1,36(0,83 ; 1,96)$ & $1,51(0,67 ; 5,43)$ \\
\hline $\mathrm{LFHF}_{\mathrm{DBP}}, \mathrm{mmHg} / \mathrm{mmHg}^{2}$ & $4,67(2,02 ; 7,67)$ & $3,76(2,16 ; 8,35)$ & $3,80(2,10 ; 5,90)$ \\
\hline
\end{tabular}

* - p<0.05 in comparison "High" and "Average" with "Low"; \# - p<0.05 in comparison "High" with "Average"

Having analyzed the DBPV data it seems obvious that in terms of VLFDBP (mmHg2) probable differences between "high" and "low" are quite noticeable (Table 3). It is due to this component that DBPV value differs significantly from TPDBP $\left(\mathrm{mmHg}^{2}\right)$ in "high" from "low". And given the data of other scholars [26-28], we can assume that the activity of angiotensin II and Nitric oxide synthase (NOS) that are associated with the VLF range of DBPV in "high" differs from "low". A similar conclusion can be drawn about the activity and L-type Ca2+-channels involved in the formation of vascular myogenic response and related to the occurrence of arrhythmic complications $[29,30]$. Other values of regulatory impacts on SBP and DBP in the studied groups do not differ. That is, in terms of SBPV and DBPV the "high" is different from other levels that can characterize the activity of angiotensin II and NOS, as well as L-type Ca2+- channels reduced at low VLFDBP [29].

On the other hand, at the parameter of high-frequency influences (HFDBP, $\mathrm{mmHg}^{2}$ ), at high and average levels of the FS there is a tendency to decrease the effects, which is more pronounced at high FS, and at low - the predominance of pronounced variants against the background of the almost expected distribution. The lack of differentiation according to the parameter of the ratio of low and high-frequency influences on the DBP seems informative enough.

\section{Conclusion}

The analysis of the distribution ranks of the SBPV and DBPV parameters showed that the data on the measurement of the blood pressure variability in ultra-short measurements allows a sufficiently clear differentiation of the low level of $\mathrm{H}$, which is characterized by an increase in the total power of regulatory influences on the SBP and DBP due to supra-segmental effects and sympathetic effects, as well as an increase in low-frequency effects on DBP. The data obtained will further unify the individual options for assessing regulatory influences on blood pressure.

\section{References}

1. Apanasenko GL, Popova LA, Maglyovanyiy AV (2012) Sanology. Fundamentals of health management. Lambert Academic Publishing pp. 404.

2. Castiglioni P, Parati G, Civijian A, Quintin L, Di Rienzo M (2009) Local scale exponents of blood pressure and heart rate variability by detrended fluctuation analysis: Effects of posture, exercise, and aging. IEEE Trans Biomed Eng 56(3): 675-684.

3. Guzii OV, Romanchuk AP (2018) Determinants of the functional state of sportsmen using heart rate variability measurements in tests with controlled respiration. Journal of Physical Education and Sport 18(2): 715-724.

4. Guzii OV, Romanchuk AP (2017) Heart rate variability during controlled respiration after endurance training. Journal of Physical Education and Sport 30: 2024-2029.

5. Meeusen R, Duclos M, Foster C, Fry A, Gleeson M, et al. (2013) Prevention, diagnosis, and treatment of the overtraining syndrome: Joint consensus statement of the European College of Sport Science and the American College of Sports Medicine. Med Sci Sports Exerc 45(1): 186-205.

6. Berge HM, Isern CB, Berge E (2015) Blood pressure and hypertension in athletes: A systematic review. Br J Sports Med 49(11): 716-723.

7. Nobrega ACL, O'Leary D, Silva BM, Marongiu E, Piepoli MF, et al. (2014) Neural regulation of cardiovascular response to exercise: Role of central command and peripheral afferents. BioMed Res Int 20.

8. Joyner MJ, Wallin BG, Charkoudian N (2016) Sex differences and blood pressure regulation in humans. Exp Physiol 101(3): 349-355.

9. Karemaker JM (2017) An introduction into autonomic nervous function. Physiol Meas 38(5): R89-R118. 
10. Pagani M, Furlan R, Dell'Orto S, Pizzinelli P, Baselli G, et al. (1985) Simultaneous analysis of beat by beat systemic arterial pressure and heart rate variabilities in ambulatory patients. J Hypertension Suppl 3(3): S83-85.

11. Gesche H, Grosskurth D, Küchler G, Patzak A (2012) Continuous blood pressure measurement by using the pulse transit time: Comparison to a cuff-based method. Eur J Appl Physiol 112(1): 309-315.

12. Kounalakis SN, Geladas ND (2009) The role of pulse transit time as an index of arterial stiffness during exercise. Cardiovasc Eng 9(3): 92-97.

13. Porta A, Gasperi C, Nollo G, Lucini D, Pizzinelli P, et al. (2006) Global versus local linear beat-to-beat analysis of the relationship between arterial pressure and pulse transit time during dynamic exercise. Med Biol Eng Comput 44: 331-337.

14. Guziy OV, Romanchuk AP (2016) Sensitivity of arterial baroreflex in the terms of body recovery after training load. Medical Jour 3(96): 24-30.

15. Guziy OV, Romanchuk AP (2017) Differentiation of Hemodynamics of Top Athletes Depending on Heart Rate Variability after Training. Journal of Advances in Medicine and Medical Research 22(3): 1-10.

16. Castiglioni P, Di Rienzo M, Radaelli A (2013) Effects of autonomic ganglion blockade on fractal and spectral components of blood pressure and heart rate variability in free-moving rats. Autonomic Neuroscience: Basic and Clinical 178(1-2): 44-49.

17. Cherepov A, Pozdeeva D, Arkhipova E (2015) The choice of informative parameters of the cardiovascular system for assessment of physiological effects of hypogravity. American Journal of Life Sciences 3(1-2): 48-57.

18. Parati G, Saul JP, Di Rienzo M, Mancia G (1995) Spectral analysis of blood pressure and heart rate variability in evaluating cardiovascular regulation. A critical appraisal Hypertension 25(6): 1276-1286.

19. Parati G, Stergiou G, Dolan E, Bilo G (2018) Blood pressure variability: Clinical relevance and application. Journal of Clinical Hypertension 20(7): 1133-1137.

20. Guziy OV, Romanchuk AP (2017) Multifunctional determinants of athletes' health. Journal of Medicine and Health Research 2(1): 12-21.

21. Pivovarov VV (2011) Information-measuring system for functional diagnostics of nervous regulation of blood circulation. Part II. The implementation. Automation and remote control 72(3): 671-676.

ISSN: 2574-1241

DOI: 10.26717/BJSTR.2018.10.001943

Romanchuk AP. Biomed J Sci \& Tech Res

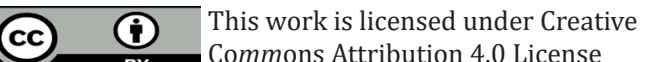

Submission Link: https://biomedres.us/submit-manuscript.php
22. Romanchuk AP, Dolgier YV (2017) Effects of long-term training experience of aerobic exercises on middle-aged women. Journal of Physical Education and Sport 17(2): 680-687.

23. Ternovoi KS, Romanchuk AP, Sorokin M Yu, Pankova NB (2012) Characteristics of the Functioning of the Cardio-Respiratory System and Autonomic Regulation in Para-Athletes with Spinal Injury. Human Physiology 38(4): 410-415.

24. Akselrod S, Gordon D, Madwed JB, Snidman NC, Shannon DC, et al. (1985) Hemodynamic regulation: Investigation by spectral analysis. Am J Physiol 249(4): H867-875.

25. Cheng WH, Lu PJ, Ho WY, Tung CS, Cheng PW, et al. (2010) Angiotensin II inhibits neuronal nitric oxide synthase activation through the ERK1/2RSK signaling pathway to modulate central control of blood pressure. Circ Res 106(4): 788-795.

26. Chowdhary S, Townend JN (2001) Nitric oxide and hypertension: not just an endothelium derived relaxing factor! J Hum Hypertension 15(4): 219-227.

27. Gamboa A, Shibao C, Diedrich A, Choi L, Pohar B, et al. (2007) Contribution of endothelial nitric oxide to blood pressure in humans. Hypertension 49 (1):170-177.

28. Langager AM, Hammerberg BE, Rotella DL, Stauss HM (2007) Very lowfrequency blood pressure variability depends on voltage-gated L-type Ca2+ channels in conscious rats. Am J Physiol Heart Circ Physiol 292(3): 1321-1327.

29. Radaelli A, Castiglioni P, Centola M, Cesana F, Balestri G, et al. (2006) Adrenergic origin of very low-frequency blood pressure oscillations in the unanesthetized rat. Am J Physiol Heart Circ Physiol 290(1): H357-H364.

30. Romanchuk AP (2013) The Complex Approach to a Multipurpose Estimation of a Sportsmen Condition, In: Polysystemic Approach to School, Sport and Environment Medicine, M Karganov (eds); OMICS Group eBooks p. 54-86.

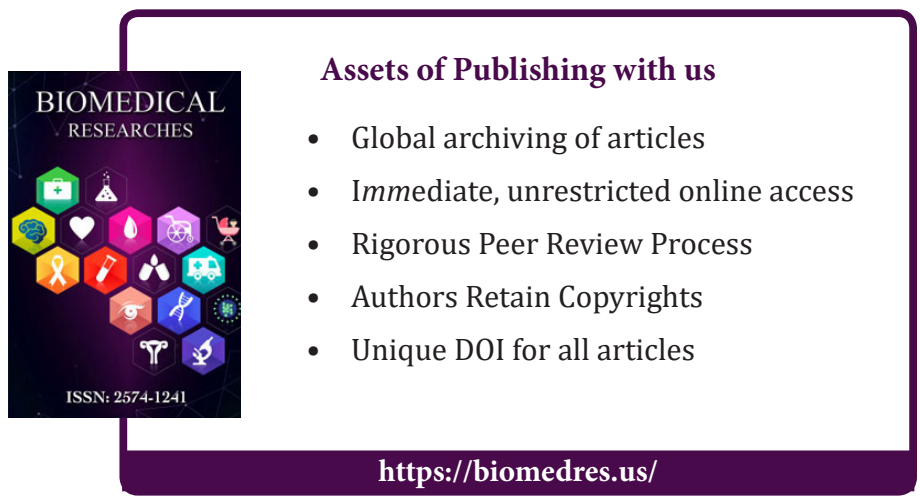

Cite this article: Romanchuk AP, Guzii OV. Level of Athlete’s Health and Blood Pressure Variability. Biomed J Sci\&Tech Res 10(3)-2018. BJSTR. 